\title{
(IN)VISIBILIDADE DE MULHERES SEM ROSTO: ÉTICA E POLÍTICA EM IMAGENS FOTOGRÁFICAS DE TERESA MARGOLLES
}

\author{
Ângela Marques \& Angie Biondi
}

\begin{abstract}
RESUMo
$\mathrm{Na}$ contramão dos quadros morais produzidos pelos discursos fotojornalísticos tradicionais e pela cobertura mediática dos casos de femicídio no cotidiano, a artista mexicana Teresa Margolles cria obras onde a brutalidade de assassinatos em série conecta o sofrimento individual a uma responsabilidade ética coletiva. Neste texto, analisaremos as construções fotográficas de duas obras recentes da artista mexicana: La búsqueda (2014) e Pesquisas (2016). A partir das noções de vulnerabilidade e de precariedade (Butler, 2006; Butler et al., 2016), argumentamos que a relação entre violência e gênero no trabalho de Margolles é apresentada sob a forma da resistência, dirigindo-se a um comum enquanto espaço público polémico (Rancière, 2004), e instaurando a possibilidade de uma cena de interpelação (Butler, 2015). Consideramos ainda que estas obras, onde os sofrimentos individuais foram articulados em uma narrativa complexa, passíveis de interpelar os espectadores, compõem um gesto estético-político, que se acorda com a política das imagens reivindicada por pensadores como Jacques Rancière (2010b) e Georges Didi-Huberman (2012). A dinâmica política e estética que atravessa as fotografias de Margolles é relacionada ainda com a responsabilidade ética implícita na noção de rosto em Emmanuel Levinas (1982).
\end{abstract}

\section{Palavras-chave}

Femicídio; imagem; vulnerabilidade; política da estética; rosto

\begin{abstract}
In the opposite side of these moralizing pictures produced by traditional journalistic and photojournalistic narratives, the Mexican artist Teresa Margolles creates art works that disclose the vulnerable condition of women in the brutality of serial murders in order to connect individual suffering to a collective ethics of responsibility. In this text, the analytical work focuses on two of Margolles recent art works: La búsqueda (2014) and Pesquisas (2016). Taking the concepts of vulnerability and precariousness (Butler, 2006; Butler et al., 2016), we argue that the relation between violence and gender in Margolles's art work is presented as resistance addressing a common as polemical public space (Rancière, 2004), and giving place to the possibility of an interpellation scene (Butler, 2015). We also consider that this photographic work, which articulates individual sufferings in a complex narrative capable to invite spectators to a careful and reflexive contemplation, give rise to a political and aesthetical gesture that can be related to a politics of the images as it is argued by Jacques Rancière (2010b) and Georges Didi-Huberman (2012). The political and aesthetical dynamics crossing Margolles photographs is also related to the ethical responsibility voiced by Emmanuel Levinas (1982) concept of face.
\end{abstract}

KEYWORDS

Femicide; image; vulnerability; politics of aesthetics; face 


\section{INTRODUÇÃo}

Seria um erro pensar que é só uma questão de encontrar a imagem justa e verdadeira para que certa realidade seja transmitida. A realidade não é transmitida pelo que representa uma imagem, mas pelo desafio que a própria realidade constitui para a representação. (Butler, 2006, p. 182)

Segundo Ana Carcedo (2010, p. 28), em uma pesquisa sobre o femicídio na América Central, a violência cometida contra mulheres em Juarez (Estado de Chihuahua, México) apresenta dois tipos de mensagens: uma vertical, na qual os agressores reiteram a dominação masculina sobre a vida ou a morte das mulheres locais; outra horizontal, onde os homens usam o femicídio como estratégia para demarcar territórios de poder e de negócios. Esta última fica muito evidente nos inúmeros casos registrados de agressões e mortes de mulheres como forma de vingança aos grupos rivais. De todo modo, ambas reiteram a subordinação feminina.

A pesquisa ainda aponta como as mulheres em Juarez estão expostas a uma complexa teia de agentes violentos, incluindo espaços institucionalizados (Estado, família, polícia e mídia) e poderes paralelos como o tráfico e as milícias armadas. Há um processo contínuo de violência contra as mulheres que não se reduz a casos isolados, crimes passionais ou de proximidade. Chama a atenção o fato de o femicídio ser noticiado pelos jornais de forma a particularizar os crimes, como se não houvesse qualquer tipo de relação entre eles. Além disso, as vozes que os narram são em geral masculinas (policiais, jornalistas, agentes de investigação, etc.), e acabam por reforçar as justificativas apresentadas pelos homens agressores, ainda que tenham ressalvas acerca da brutalidade dos atos cometidos.

Caldeira (2017) destaca como o assassinato de mulheres ganha visibilidade nos jornais, onde vítima e agressor aparecem em lugares estanques, sem que o texto jornalístico relate as especificidades de suas relações. Com isso, as mortes são individualizadas e as narrativas reforçam estereótipos que culpabilizam as mulheres e obscurecem a responsabilidade dos agressores. Para a autora, cobra-se da mulher que preveja seu próprio assassinato e se afaste do agressor, mas o jornalismo não pergunta se aquela mulher tinha condições para sair do relacionamento. Ou seja, quase não se encontra uma reflexão acerca das condições e situações nas quais as escolhas e ações dessas mulheres são definidas e assim apagam assimetrias de poder, desigualdades e injustiças de toda a ordem. Não há indagações sobre os recursos, materiais e simbólicos, disponíveis no processo em que as mulheres se constituem como sujeitos de suas vidas (Blay, 2008). São esses recursos que permitiriam às mulheres o exercício da autonomia, a definição de projetos de vida considerando-se os constrangimentos de poder, as limitações econômicas, sociais e histórias e as assimetrias que limitam e, por isso mesmo, definem as possibilidades da ação individual e da ação dessas mulheres vítimas de violência em concerto com outros indivíduos (Biroli, 2016).

É nesse contexto de constrangimentos e limitações que as mulheres de Juarez fazem escolhas, elaboram, experimentam modos de vida que resultam de uma mistura 
entre o que desejam e o que podem ser e fazer. Não podemos tampouco esquecer que a vida criminosa também se define como possibilidade para as mulheres de Juarez'.

Nesse sentido, o que Blay (2008), Carcedo (2010) e Caldeira (2017) destacam é que o jornalismo e suas narrativas constroem uma memória coletiva das mortes de mulheres: produzem uma ferida coletiva a partir de uma ferida individual, mas essa memória muitas vezes resulta em nova morte e silenciamento das mulheres, uma vez que o assassinato particularizado reitera uma culpabilização da mulher. Trata-se de um processo de invisibilidade configurado justamente através da visibilidade. Os enquadramentos midiáticos preferenciais utilizados no processo de narrativização dessas mortes servem-se de quadros coletivos de valores hierarquizados para atribuir, ou não, valorização ou estima social às vítimas e agressores. É em função desse horizonte comum que são elaborados os critérios de valorização ou depreciação coletivas de sujeitos ou formas de vida (Butler, 2011). Nesse caso, a invisibilidade não se relaciona a uma ausência física, mas sim a uma não existência social e comunicacional. As mulheres assassinadas não falam, porque suas vozes não são escutadas: não interpelam, não recebem respostas e não são reconhecidas como moralmente dignas de serem valorizadas. Sua inexistência enquanto interlocutoras e a destituição de sua autoridade e legitimidade moral para dialogar configuram sua invisibilidade e ostracismo social.

$\mathrm{Na}$ contramão do silenciamento e invisibilidade frequentemente produzidos pelos discursos (foto)jornalísticos tradicionais (que, não raro, se torna cúmplice e agente de violência - ver Picado, 2014), a artista mexicana Teresa Margolles criou uma instalação que revela a brutalidade de assassinatos em série de mulheres onde não é o sofrimento individual singular e noticiado que conta, mas o valor do traumatismo que acompanha os acontecimentos e as vítimas que esses acontecimentos vão permitir qualificar.

Em La búsqueda (2014) e Pesquisas (2016), cujas imagens são objeto de reflexão neste texto, Margolles apresenta grandes painéis formados por placas de vidros em um fundo preto onde estão colados cartazes que buscam por informações de mulheres desaparecidas na cidade de Juarez, no México. Ela não apresenta nenhuma notícia, documento ou registro sobre o paradeiro destas mulheres, mas faz da instalação uma espécie de obituário do femicídio² naquela cidade.

Partindo desta contraposição entre o discurso jornalístico tradicional e as obras de La búsqueda (2014) e Pesquisas (2016) da artista mexicana Teresa Margolles, este artigo toma como fio condutor três dimensões da relação entre visibilidade e invisibilidade que são exploradas nas seções que o estruturam: a) a tensão entre silêncio e fala como produtora de

\footnotetext{
' Em Juarez o crime entrelaça "traficantes de drogas, armas e pessoas, lavadores de dinheiro, guarda-costas, pistoleiros e as novas musas de uma contenda exibicionista: as pistoleiras. Chegar a ser uma matadora famosa como La Guera Loca, acusada de dezenas de assassinatos e filmada enquanto decapitava uma vítima, é o que ambicionam algumas meninas pobres e temerosas, quando se alistam inicialmente como "mensageiras", o escalão inferior na pirâmide criminosa, de onde podem ascender a posições, até se converterem em "linces" e "condores". Diz-se que elas matam com mais frieza que seus colegas homens, que são mais profissionais e não são movidas por nenhuma pulsão erótica (que os homens teriam): o que as motiva é unicamente o objetivo de ganhar dinheiro e subir na estrutura mafiosa" (Pignotti, 2012).

2 O Centro de Investigaciones y Estudios Superiores en Antropologia Social (CIESAS) do México investiga o feminicídio na Cidade de Juarez desde 1998. Desde então, o Centro tem denunciado os altos índices da violência contra mulheres praticados na cidade reiterando como característica a brutalidade peculiar dos casos registrados.
} 
"vulnerabilidades" e da "precariedade" dos sujeitos enquanto interlocutores dignos de consideração e escuta em uma "cena de interpelação" (Butler, 2015); b) a tensão entre sensível3 e visível e entre estética e política que marca as possibilidades de resistência nas imagens fotográficas e que será fundamentada sobretudo através do pensamento de Jacques Rancière e de Georges Didi-Huberman; e c) a tensão entre a face humana e o rosto levinasiano, entendido como clamor de sofrimento, como fala que interpela e convoca à responsabilidade ética (Levinas, 1982; Agamben, 2000, Biondi \& Marques, 2016).

\section{Entre imagens: La Búsqueda e Pesquisas}

O trabalho artístico de Teresa Margolles, de alguma forma, sempre dialoga com a morte, mais especificamente, com os vestígios materiais que a compõem: um pedaço da língua de um usuário de drogas assassinado (Lengua, 2000), o fragmento de uma parede cravejado de balas pela guerra do tráfico (Frontera, 2010), os restos da água usada para lavar os corpos de cadáveres (En el Aire, 2003), entre outros. Em La búsqueda (2014), ela está interessada nos traços ligados ao desaparecimento de mulheres vítimas de assassinato. Ao transportar os restos de cartazes para a sala de exibição de um museu, ela ressalta o efeito do tempo e das intervenções urbanas sobre essas peças assegurando a criação de uma memória a partir dos vestígios.
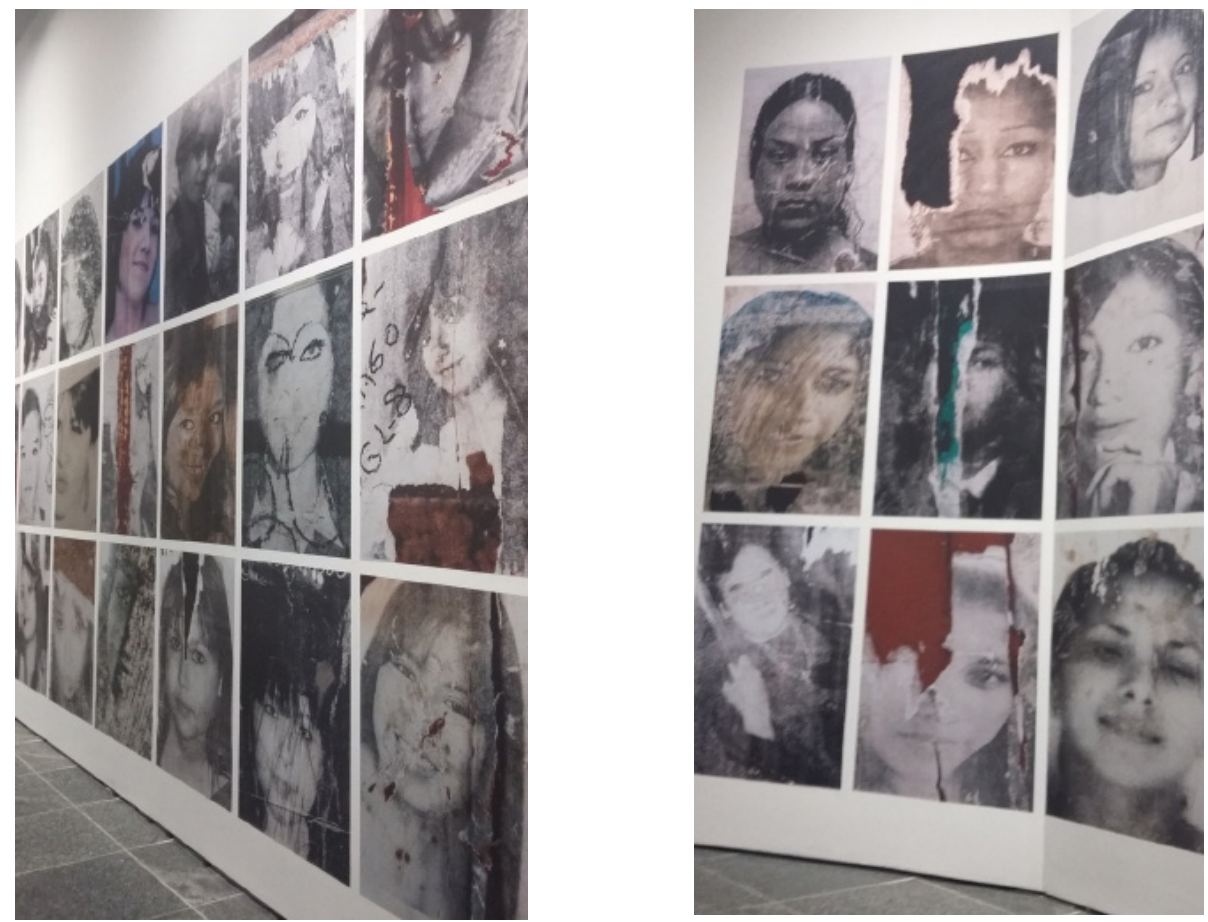

\footnotetext{
${ }^{3}$ Consideramos que o sensível não se reduz ao visível, ou seja, aquilo que estabelece a distribuição desigual de reconhecimento e escuta entre os sujeitos não é dado a ver, embora seja justamente o que articula enquadramentos, normas e códigos que formatam e controlam a vida coletiva. Temos como pressuposto o fato de que a política da estética (Rancière, 2012) está intrinsecamente ligada ao modo como, nas imagens, operações constituem regimes de visibilidade capazes de regular e constranger o "aparecer" dos sujeitos, além de construir regulações para a distância do espectador com relação à obra de modo a evitar um contínuo confuso onde se perde toda a probabilidade de alteridade e estranhamento.
} 

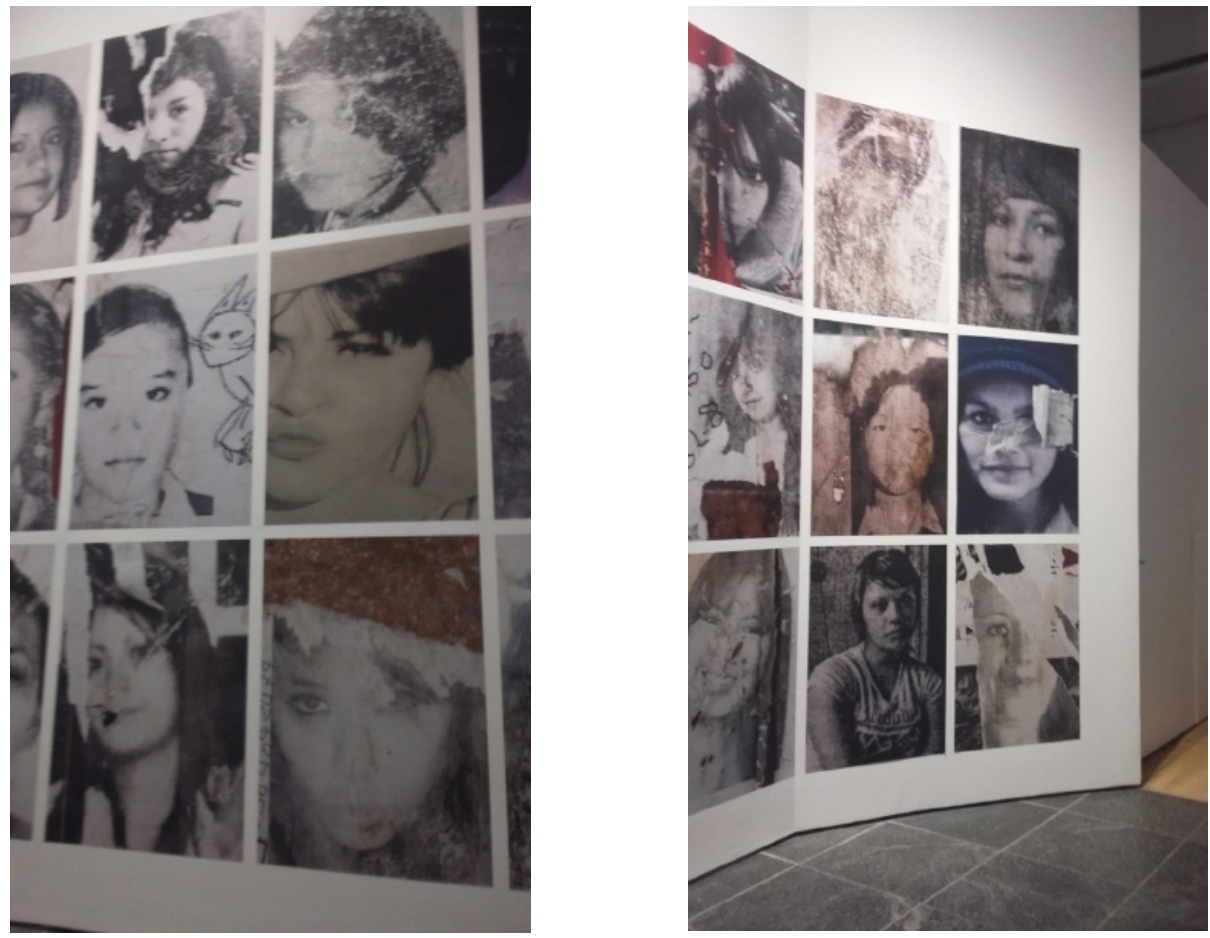

Figura 1: Pesquisas, Teresa Margolles, 2016, Exposição Mundos, Musée d'Art Contemporain de Montréal, março de 2017

Créditos: Fotografia de Angie Biondi

Os cartazes que integram a instalação são tão comuns que se tornam parte da paisagem da cidade, diluindo-se na arquitetura e naturalizando-se ao olhar. As pessoas que por eles passavam raramente deviam refletir acerca do destino das mulheres procuradas: o rosto delas vai desaparecendo e passando de uma recordação a um adorno nas paredes de Juarez; de uma busca a um esquecimento e apagamento de suas histórias.

Nas peças é possível ver as fotografias das vítimas, todas datadas em um período recente à exposição. Os vidros que compõem os painéis são provenientes das janelas das lojas da cidade onde estavam colados os diversos pedidos e apelos por qualquer informação sobre o sumiço destas mulheres.

Diante da notória realidade de violência contra mulheres registrada na cidade mexicana não parece necessário apresentar mais uma notícia ou dados estatísticos que indiquem a morte como a maior probabilidade destes desaparecimentos. A existência documentada das jovens é vista apenas nas fotografias de cartazes, afixados nestes pedaços de papel já gastos pelo tempo, sujos, alguns rabiscados, outros amassados pelo excesso de cola, rasgados e dividindo espaço dos vidros com inúmeros outros cartazes, panfletos, publicidade de todo tipo.

Enquanto o visitante atravessa o corredor com a sensação de ser vigiado pelos inúmeros olhares que restaram destes rostos, ouve a reprodução do áudio de um trem como se passasse por uma rua, até sumir pelo corredor, intensificando ainda mais a presença daquele pedaço do espaço real da cidade. A sensação de morbidez é crescente e provocadora. 
Estes mesmos materiais foram utilizados pela artista para compor outra obra, essencialmente fotográfica. Pesquisas(2016) é composta pelas mesmas imagens retiradas dos cartazes das desaparecidas. Nela, Margolles amplia os rostos das mulheres e, com eles, compõe grandes murais com cerca de 30 fotografias (Figura 1).

O grande formato e a disposição das fotos em longos painéis distribuídos pelos corredores da galeria enfatizam a dimensão ampliada dos rostos, de modo a atribuir magnitude à biografia de cada uma das vítimas, ainda que expressas por meio de uns poucos traços e vestígios. Trata-se de uma grande mirada destas mulheres que buscam pelos olhares dos que caminham entre os corredores. Não é Margolles quem inquire ou interpela, mas os olhos daqueles rostos e vidas ali dispostas que, sabemos, já desaparecidas e vitimadas.

\section{PARA UM ESPAÇO DE INTERPELAÇÃo: ENTRE PRECARIEDADE E VULNERABILIDAdE}

Neste artigo, argumentamos que a relação fulcral entre violência e gênero nas fotografias de Teresa Margolles não está circunscrita aos resultados de uma agressão, a oferecer uma face espancada, um corpo baleado e disforme, ou ainda provar, por hematomas e sangramentos, o registro de uma violência que legitimaria um lugar à mulher na condição de vítima, tal como faz o jornalismo, entre outros regimes midiáticos. O gesto enunciativo, tanto poético quanto político, nas fotografias de Margolles não se restringe a fazer e compartilhar um registro apenas, mas busca promover uma interpelação e abrir um espaço polémico, provocando uma ruptura com as conformações dos quadros discursivos acerca da imagem de uma vítima, aqui ocupada pelas mulheres desaparecidas e assassinadas na cidade de Juarez, conhecida pelos altos índices de femicídio desde 1990.

Na nossa perspectiva, quando nos preocupamos não apenas em descrever o modo como a representação se constitui em uma imagem, mas buscamos investigar as relações sociais, históricas, culturais e as ideologias que perpetuam tal representação, passamos a indagar acerca de como algumas normas tácitas operam para tornar certos sujeitos pessoas reconhecíveis e tornar outros mais difíceis de reconhecer. O problema, quando se aborda a relação entre violência e gênero, segundo Butler "não é apenas saber como incluir mais pessoas nas normas existentes, mas sim considerar como as normas existentes atribuem reconhecimento de forma diferenciada" (2015, p. 20). Nesta dependência estariam conjugadas as condições de precariedade e vulnerabilidade dos sujeitos.

Neste caso, é possível observar que a precariedade da vida pode se manifestar no modo como espaços de aparência, frequentemente demarcados pelas imagens e enquadramentos midiáticos, produzem formas diferentes de distribuir a vulnerabilidade fazendo com que algumas populações e grupos estejam mais sujeitos à violência que outros. Nesses espaços, aqueles que permanecem sem face, ou cujas faces são apresentadas como símbolos de inferioridade e subordinação, geralmente não são considerados dignos de reconhecimento. Butler afirma que "se o reconhecimento caracteriza um ato, uma prática ou mesmo uma cena entre sujeitos, então a condição de ser reconhecido caracteriza as condições mais gerais que preparam ou modelam um sujeito para o reconhecimento" (2015, p. 19). Assim, 
é extremamente importante conhecer os termos, as convenções e as normas gerais que atuam na produção de enquadramentos de forma a moldar um indivíduo em um sujeito reconhecível.

Sabemos, segundo Butler, que vulnerabilidade e precariedade são interdependentes, mas há diferenças tanto conceituais quanto pragmáticas em seus significados. A vulnerabilidade é recorrentemente associada com a vitimização ou a incapacidade de ação. É importante atentar para o modo como discursos de vulnerabilidade e proteção rotulam indivíduos e grupos como vulneráveis e se isso leva à discriminação, estereotipagem e intervenções paternalistas indesejáveis. Nesse sentido, uma pessoa pode ser considerada vulnerável na medida em que não está em uma posição de prevenir ocorrências que minariam o que ela pensa ser importante para ela.

A vulnerabilidade, para Butler (2006), conecta-se a uma questão de controle efetivo, ou de equilíbrio entre o poder que a pessoa tem de conduzir sua vida e as forças que a influenciam. As condições em que as pessoas fazem escolhas e tomam decisões, os contextos e assimetrias de poder que os perpassam, assim como as táticas para ligar com os constrangimentos e barreiras são essenciais para compreendermos a vulnerabilidade não como condição biológica inata ou como falta, carência e anulação da agência individual e coletiva, mas como abertura à construção negociada de si e de projetos de vida. O modo como as pessoas elaboram projetos e objetivos, identificando, antevendo e enfrentando forças opressoras coloca a vulnerabilidade em contato com as noções de autonomia e resistência.

Sob esse aspecto, a reflexão de Butler et al. (2016) salienta uma definição de vulnerabilidade distanciada de uma disposição ou característica subjetiva, ou mesmo uma condição existencial. Para as autoras, a vulnerabilidade nomeia um conjunto de relações com um campo de objetos, forças, processos vitais, instituições e seres que incidem sobre nós e nos afetam de alguma maneira. A vulnerabilidade assim entendida configura-se entre nossa passibilidade (somos afetados) e nossa capacidade de agência. Diante das relações que configuram a vulnerabilidade, temos diferentes modalidades e graus de passibilidade e resposta que operam juntas implicando sobretudo nosso corpo político.

Nas fotografias de Margolles, as mulheres compõem um sujeito social atado à dupla condição. A vulnerabilidade física - declarada, denunciada - se revelaria, também, vulnerabilidade de um tipo de sujeito, neste caso, as mulheres, que procuram se afirmar, ainda que como vítimas, legítimas e reconhecidas, diante do olhar do outro. Suas faces e vidas são colocadas nas obras fotográficas de modo a funcionar como uma convocação, um chamamento, um apelo à sua existência. Deste modo, a vulnerabilidade do sujeito e da imagem se colocaria urgente ao olhar. Assim também a condição é precária, uma vez que suas vidas estão sempre, de alguma forma, nas mãos do outro. De acordo com Butler, "a vida precária é a condição de estar sob uma condição politicamente induzida, na qual certas populações sofrem com redes sociais e econômicas de apoio deficientes e ficam expostas de forma diferenciada às violações, à violência e à morte" (2015, p. 46).

As fotografias de Margolles buscam perceber modos de vulnerabilidade que informam modos de resistência, questionam enquadramentos que recusam formas de agência política desenvolvidas em condições de dureza pelas mulheres vítimas de violência. 
Ela transforma a vulnerabilidade em uma exposição deliberada diante do poder e do estranhamento do espectador, de modo a construir uma resistência política como ato corporal. Aqui a vulnerabilidade se encontra com a precariedade, pois é a condição de vulnerabilidade que nos lembra (e vice-versa), segundo Butler (2011), que todos nós somos sujeitos precários, uma vez que dependemos de outros anônimos para sermos apreendidos, considerados e reconhecidos. Estamos vulneráveis e, por isso, somos precários. Nesta interdependência estaria a condição de precariedade e vulnerabilidade conjugadas, especialmente, quando atribuída aos crimes de gênero.

Assim, se o jornalismo se restringe a revelar traumas individuais e localizados para, a partir deles explorar um impacto emocional junto aos leitores, podemos dizer que Margolles, ao contrário, se interessa pelos traumatismos ${ }^{4}$ que conectam o sofrimento individual ao comum, à possibilidade de, com seu trabalho, construir um enunciado e instaurar a possibilidade de uma "cena de interpelação" (Butler, 2015) para essas mulheres. O jogo enunciativo configurado nessa cena apresenta as forças morais visíveis que atuam na produção discursiva do sujeito para com os outros, isto é, o "conjunto de regras e normas que um sujeito deve negociar de maneira vital e reflexiva" (Butler, 2015, p. 21). A cena de interpelação é a dimensão intervalar na qual nos remetemos uns aos outros e a nós mesmos preservando as diferenças e construindo um espaço comum na experiência de proximidade e comunidade.

As imagens e as narrativas jornalísticas sobre o crime de género não conseguem na maior parte das vezes que o trauma que envolve a morte violenta se transforme em um traumatismo experienciado coletivamente, criando solidariedades através da dor. Em outras palavras, recorrendo ao seu quadro comum de sentidos, o jornalismo não consegue na maior parte das vezes criar um "comum", ou seja, um espaço vazio no qual damos forma ao "entre nós" e à reciprocidade, um espaço de escuta e de acolhimento de outras existências e temporalidades sem, contudo, estar isento das distinções e das distâncias (Mondzain, 2011). O comum dificilmente emerge via enquadramento midiático, uma vez que ele tende a produzir vítimas cujas vidas exemplificam comportamentos considerados inadequados e condutas condenáveis.

O comum é aqui entendido como o lugar de exposição e aparecimento dos intervalos e das brechas que permitem uma ação comum através da linguagem, de modo a promover não apenas formas de "ser em comum" (que muitas vezes apagam ou incorporam diferenças, suprimindo singularidades), mas formas de "aparecer em comum" (Tassin, 2004). Eis aqui uma questão central: o "comum" de uma comunidade diz do "aparecer" dos sujeitos e de seus rostos na esfera de visibilidade pública, ao mesmo tempo como interlocutores dignos de respeito e estima e como sujeitos cuja vida é estimável e reconhecível como válida. Aparecer é falar, ganhar existência pública como interlocutor: ganhar rosto (Levinas, 1982) e interpelar, num espaço público polémico e marcado pelo "dissenso" (Rancière, 2004).

\footnotetext{
${ }^{4}$ A diferença entre trauma e traumatismo aparece nas reflexões de Didier Fassin (2007, 2014). Segundo ele, o trauma está ligado à emoção associada ao intolerável sofrimento. A memória machucada, traumática reflete a dor que atesta a realidade do acontecimento. O traumatismo está associado a uma memória coletiva de acontecimentos intoleráveis. Assim, o trauma, quando acessa a dor e a conecta um coletivo, produz um o acontecimento potente, o traumatismo. E é o traumatismo que pode, segundo Fassin, possibilitar recursos contra a vitimização ao tornar a vítima protagonista de seus discursos.
} 
Para Rancière (2004), a construção de um comum opõe um espaço consensual a um espaço polêmico: faz aparecer sujeitos e falas que até então não eram contados ou considerados; ela traz à experiência sensível vozes, corpos e testemunhos que não eram vistos como pertencentes ao regime igualitário. A comunidade consensual, ao não registrar essas vozes, corpos e testemunhos como interlocutores, estabelece um dano que deve ser discutido em um espaço público polêmico. "Esse procedimento cria uma comunidade de partilha no duplo sentido do termo: um espaço que pressupõe o compartilhamento da mesma razão, mas também um espaço cuja unidade só existe por meio da divisão" (Rancière, 2004, p. 166).

Enfim, as vítimas no trabalho de Margolles adquirem uma forma de apresentação que se mostra resistente: sofrimentos individuais foram organizados e articulados em uma narrativa complexa, capaz de ser expressa publicamente e de interpelar eticamente os espectadores e demandar atenção, interpelação e escuta. A exposição criada através das fotografias de La búsqueda elabora o traumatismo que, de um lado, confere a palavra a quem sofre(u) e apresenta vítimas dotadas de agência (contrapostas à passividade e inação): aptas, em sua vulnerabilidade, a oferecer pistas de seu cotidiano, a recontar vislumbres de suas existências, das violências sofridas e das humilhações, inseguranças e incertezas circundantes. São imagens que questionam a naturalização do "comum" de uma comunidade e dos modos de apreensão sensível e reconhecimento social de sujeitos marginalizados.

\section{PARA UMA POLÍTICA DA IMAGEM: VISIBILIDADE E INVISIBILIDADE}

Ao que mais é preciso recorrer para alertar sobre a violência cotidiana que abate, e mesmo aniquila, milhares de mulheres a cada ano? As obras da artista mexicana Teresa Margolles procuram traçar outro caminho para estabelecer uma relação entre a imagem, a realidade e o olhar. Se não podem ser classificadas como fotografias puramente artísticas, tampouco podem ser enquadradas como fotografia policial ou jornalística. As obras de Margolles propõem imagens fora dos gêneros e entrecruzam criminalística, testemunho, estatística, sociologia, arte. Uma outra perspectiva possível para lidar com o incômodo das obras é atentar para o gesto da artista a partir de uma política da imagem. Partindo da crítica à lógica ocidentalizada de tudo mostrar e tudo ver das imagens que povoam o cotidiano, as imagens de Margolles se propõem percorrer outra via: expor a produção paradoxal da visibilidade como invisibilidade.

Em textos-chave que têm sido usados em muitas discussões sobre a imagem no âmbito das artes e mesmo da comunicação mediatizada (Rancière, 2009, 2010a, 2010b; Didi-Huberman, 2008), indica-se a necessidade de restituir um debate onde a visibilidade seja, antes de tudo, a revelação de maneiras de fazer e de modos de pensar a imagem incluindo aí a produção de sua invisibilidade. Se o acesso às realidades do mundo parece cada vez maior e de modo quase instantâneo, dada a sofisticação dos aparatos tecnológicos de captação e difusão de imagens online, por outro lado, ainda se revela muito pouco sobre a condição na qual são vistas. Neste sentido, a proliferação dos gestos de captação do mundo em imagens revelaria sua base paradoxal. Segundo o autor, a 
sobre-exposição leva à subexposição. Neste texto, indagamos se não padecem, também, da invisibilidade, as inúmeras violências e mortes de mulheres quando inscritas pela rubrica jornalística, policial ou estatística. Ao contrário desta proliferação de imagens de vítimas que circulam pelos diversos meios e veículos, o trabalho de Margolles se apresenta por parcos materiais do cotidiano. Inverter esta direção do olhar faz com que possamos compreender a distinção entre o regime da representação, aquilo que compõe o conteúdo - a imagem visível - e o regime do dispositivo no qual a imagem está integrada - a imagem dizível - e por onde se movimenta.

Segundo Didi-Huberman (2008), a imagem exige de nós uma ação de equilibristas, uma vez que nos posicionamos, por meio da mirada, entre o espaço ético da implicação e da explicação (crítica, comparação, montagem). Tanto para ele quanto para Rancière (2007) não estaríamos diante das imagens, mas entre elas. Neste caso, estar entre imagens significa tomar uma posição, ter uma perspectiva, enfim, requer uma implicação na imagem pelos movimentos de apropriação, de conhecimento e, simultaneamente, de auto-constituição para nos aproximarmos do Outro.

O modo como Didi-Huberman e Rancière, ambos convocando explicita ou implicitamente Walter Benjamin, caracterizam a operação de montagem realizada no diálogo entre imagens e entre elas e outros elementos textuais pode ajudar a entender o gesto estético-político empreendido por Margolles. Em Didi-Huberman (2012) a montagem permite a emergência de um texto histórico organizado não sob a linearidade cronológica, mas sob o signo de uma vinculação dialética entre passado e presente. Permite ainda o questionamento das narrativas dominantes, a produção de outro enunciado que desmonte e interrompa o anterior, num interminável processo de destituição e restituição, permitindo a emergência do diferente. Essa elaboração requer o movimento de "acolher o descontínuo da história, proceder à interrupção desse tempo cronológico sem asperezas, e renunciar ao desenvolvimento feliz de uma sintaxe lisa e sem fraturas" (Didi-Huberman, 2012, p. 99).

Rancière (2012) também ressalta esse caráter dialético da montagem, que aproxima elementos heterogêneos e gera estranhamento, em contraposição ao que ele nomeia de montagem simbólica, a qual teria o efeito de harmonizar e articular imagens de violência e de revolta propondo uma forma de comunidade sensível consensual que se identifica via familiaridade com os elementos expostos. Na montagem simbólica, apesar de também colocar em relação elementos heterogêneos, o espectador se aproxima demais das imagens, identificando-se com elas, tornando-se incapaz de distinguir as faIhas, excessos e vazios que configuram o comum de uma comunidade. Já as montagens dialéticas, ao configurarem barreiras e distanciamentos entre a representação e o público, permitem um curto-circuito no continuum pretensamente existente entre a ativação das emoções (passibilidade) e ação prática de intervenção. Nesse caso, a politicidade da montagem estaria menos ligada a uma ativação do pathos e da consciência (por intenção do artista), e mais a maneira de conjugar o movimento e o repouso, a voz e o silêncio.

Nas obras de Margolles, mesmo como resto de matéria, suas personagens tomam forma e, reunidas em uma montagem imagética e dialética,apresentam-se para solicitar 
uma mirada e uma tomada de posição daquele que olha. Fixadas como imagem, como presença espectral ou fantasmática, elas mostram uma realidade de mundo que persiste, a despeito dos muitos desaparecimentos de suas vidas. "Janete Esparza, Patrícia Iharra, Nancy Navarro..." Cada uma das faces femininas com traços e olhares singulares possui uma história, um nome, uma vida.Contudo, não importa qual tenha sido sua existência particular, todas se reúnem no mesmo fim e comungam, do mesmo modo, o crime de gênero.

As fotografias de Margolles parecem, portanto, prolongar a busca. Porém, procuram agora pelo espectador, e por outro percurso, por outra via de representação que não a midiatizada,jornalística, mas aquela da poética - e da política - que indica outras formas de expor o outro em sua realidade. Procura nos deslocar do lugar comum das imagens formatadas, enquadradas e homogêneas para provocar outras relações do fazer-ver e do fazer-saber.

Neste ponto, pode-se dizer que as obras de Margolles afrontam diretamente uma lógica midiática responsável pela gestão e produção das (in)visibilidades que assumem certos sujeitos - as mulheres - no mundo contemporâneo, especialmente nas tantas cidades pelas quais se replicariam outras Juarez. La Busqueda incita a imaginar a vida e a morte dessas mulheres a partir dos fragmentos e lampejos das imagens como uma espécie de sobreviventes.

Imaginar exige de nós uma difícil ética da imagem: nem o invisível por excelência, nem o ícone do horror, nem o simples documento. Uma simples imagem: inadequada, mas necessária; inexata, mas verdadeira. A imagem é aqui o olho da história: sua tenaz vocação a tornar visível. Mas também ela está no olho da história: em uma zona local, em um momento de suspense visual, como no olho de um ciclone. (Didi-Huberman, 2003, p. 56)

Uma imagem sobrevivente é aquela que, segundo Didi-Huberman (2008, 2011), se recusa a tudo revelar, resiste à pressão de uma visibilidade total, ao desnudamento dos holofotes que, impondo um imperativo radical de publicidade, imprimem uma violência sobre os sujeitos/objetos retratados e também sobre o espectador. Para sobreviverem, as imagens não devem ofuscar, mas sim saber guardar a penumbra, como um convite acolhedor à contemplação demorada que desacelera o tempo em nome da emergência da relação, da experiência da afetação.

Assim, são diferentes tipos de relações que definem as imagens, aquelas que se estabelecem dentro e fora do âmbito artístico, que pré-configuram enunciados, que montam e desmontam relações entre o visível e o invisível, o dizível e o silenciável. Como afirma Rancière, "a imagem não é simplesmente o visível. É o dispositivo por meio do qual esse visível é capturado" (2007, p. 199) e os modos de sua captura.

A representação não é o ato de produzir uma forma visível, é sim o ato de dar um equivalente, coisa que a palavra faz tanto quanto a fotografia. A imagem não é o duplo de uma coisa. É um jogo complexo de relações entre o visível e o invisível, entre o visível e a palavra, entre o dito e o não-dito. 
(...) É a voz de um corpo que transforma um acontecimento sensível num outro, esforçando-se por nos fazer "ver" o que esse corpo viu, por nos fazer ver o que ele nos diz. (Rancière, 2010a, p. 139)

É aqui que a visibilidade se constitui uma questão política. A política das imagens está ligada ao modo como, nas imagens, operações constituem regimes de visibilidade capazes de regular e constranger o aparecer, a exposição dos sujeitos, além de construir regulações para a distância do espectador. Importante ressaltar que as instalações de Margolles questionam a ausência de distância entre os cartazes e os cidadãos, entre as imagens fotojornalísticas e o lugar do espectador, promovendo uma forma de violência que mistura espaços e corpos a ponto de apagar qualquer possibilidade de estranhamento e de emergência da diferença.

O problema não é saber se se deve ou não mostrar os horrores sofridos pelas vítimas desta ou daquela violência. Antes, diz respeito à construção da vítima como elemento de uma certa distribuição do visível. Uma imagem nunca está sozinha. Pertence a um dispositivo de visibilidade que regula o estatuto dos corpos representados e o tipo de atenção que merecem. (Rancière, 2010b, p. 144)

Para Rancière (2006), a política da estética se define sempre por certa desterritorialização e reorganização de temporalidades e formas perceptivas dadas. Assim, uma imagem é política não porque expressa a injustiça ou o sofrimento, mas porque revela como o tecido significante do sensível se encontra perturbado, a ponto de fazer com que indivíduos, palavras e objetos não possam mais ser inseridos no quadro sensível definido por uma rede de significações, nem encontrem mais seu lugar no sistema de coordenadas policiais onde habitualmente se localizam (Marques, 2014).

Ao colocar em evidência o entrelaçamento do documento e da escritura artística que modula a visibilidade e seu correlato ativo - a invisibilidade - das mulheres desaparecidas e assassinadas de Júarez, Margolles problematiza o gesto de tornar visível reivindicado por Rancière (2009). As fotografias manejadas em La búsqueda e Pesquisas não se colocam para compor mais um discurso sobre o femicídio, mas para resgatar as vidas desaparecidas destas mulheres dos inúmeros registros que se avolumam diariamente e enchem as mesas de delegacias ou as páginas dos jornais. A artista procura, enfim, prolongar a busca passando pela interrogação das condições desilenciamento e (in)visibilidade destas tantas mortes e desaparecimentos.

Nos espaços midiáticos de aparência, aqueles que permanecem sem face, ou cujas faces são apresentadas como símbolos de inferioridade ou inumanidade, geralmente não são dignos de reconhecimento. O que há é certa violência na moldura do que é mostrado, pois certas vidas e certas mortes permanecem não representadas ou representadas de forma a efetivar sua captura pelo esforço maquínico de realizar o apagamento e a desaparição por meio da própria representação.

No que se segue, tentaremos evidenciar que estas fotografias não se resumem à exemplaridade, não se restringem ao caráter ilustrativo ou sequer se limitam a oferecer 
uma face humana às inúmeras mulheres desaparecidas e/ou assassinadas de Juarez; antes, constituem um "rosto" (Levinas, 1982; Souza \& Marques, 2016; Biondi \& Marques, 2016).

\section{O ERGUER-SE DO ROSTO NA FOTOGRAFIA}

Os rostos acinzentados e esmaecidos nas fotografias coletadas por Margolles lembram o que Didi-Huberman (2014) nomeia como "grisalha", ou seja, a cor dos seres e das coisas que, com o passar do tempo, vão perdendo suas cores. Todavia, ele salienta que imagens em grisalha não nos apresentam nada de neutro, estável ou estritamente definido: trata-se da junção de um momento e de um movimento do tempo que passa e, ao passar, pulveriza (deposita poeira e destrói) a cor das coisas. Essa ação e poder que o tempo possui de descolorir as fotografias constitui um "meio do caminho" entre a visibilidade e a invisibilidade, "um ponto cinzento entre o que muda e o que morre" (Didi-Huberman, 2014, p.7). As imagens grisalhas de Margolles apresentam uma latência: a descoloração revela tanto uma ausência, um menos-ser e um não-poder, quanto uma potência associada à "carne da cor".

A grisalha é a representação cromática da distância temporal e sensorial. Ela "consiste em oferecer, numa mesma atmosfera de descoloração, a distância e a potência, a perda das coisas e a carne das coisas, a sua latência fenomenal" (Didi-Huberman, 2014, p.17). A matéria de apagamento presente nas fotografias das mulheres desaparecidas aqui analisadas possui a potência de reavivar seus corpos, uma vez que "uma figura cinzenta nada tem de morte, já que pode ser agitada por um ritmo, uma pulsação, um movimento de inspiração-expiração ou de sístole-diástole" (Didi-Huberman, 2014, p.19).

Levinas (1982) aposta na definição do rosto como expressão da vulnerabilidade do existente, como uma demanda ética endereçada ao outro, descrevendo sua manifestação (chamada pelo autor de "aparição") como um tipo de experiência reveladora da presença viva e da pura comunicação de um ente que se torna acessível, mas não se entrega. Assim, o rosto não se configura só como o que é ofertado à visão, mas é, sobretudo, como a manifestação de uma voz, de um clamor que permanece em devir no aparecer incapturável do outro que se dirige a nós.

Quando se vê um nariz, os olhos, uma testa, um queixo e se podem descrever, é que nos voltamos para outrem como para um objeto. (...) A relação com o rosto pode, sem dúvida, ser denominada pela percepção, mas o que é especificamente rosto é o que não se reduz a ele. (Levinas, 1982, p. 77)

O rosto, segundo Levinas (1982), nem sempre se deixa capturar por meio de conceitos ou imagens; o que dá acesso ao mundo do outro não é passível de ser escrutinizado, mas resiste infinitamente aos esforços de aproximação e apropriação. Em uma abordagem singular, Levinas revela o rosto como uma potência de contato com a alteridade, uma dimensão ética que requer o acolhimento do outro. O conceito de rosto marca uma relação de abertura para o outro, uma forma de diálogo em que um não possui o outro, nem tampouco se reconhece nele. O rosto expressa o fato de que o outro não é uma 
variação do eu e, por isso, não pode ser capturado ou assimilado por conceitos. Ele pode nos colocar diante de um outro que interpela, que sofre, que deseja e que nos convida a nos afastarmos de nós mesmos.

O rosto não é uma mera imagem representativa do sujeito, pelo contrário, deseja mostrar sua aparição: por isso ele afirma que o rosto possui uma visibilidade que só é apreendida pelo olhar (um olhar à escuta), na qual o outro que me olha é aquele que me revela. Deste modo, o olhar é parte integrante da manifestação e aparição de outrem. $A$ emergência do rosto como imagem fixa nas fotografias nos convida a perscrutar, a olhar o rosto e o corpo do outro, revela a imagem como importante suporte de acesso ao outro e à sua aparência (Biondi \& Marques, 2016) ${ }^{5}$.

Se somos interpelados pelo outro que nos fala, o rosto surge como verbo, como evento de palavra, como a comunicação possível que permite uma prática específica de configuração de um mundo comum, um mundo polêmico, fruto do esforço de dar forma às identidades e às alteridades. Segundo Giorgio Agamben (2000, p. 94), "compreender a verdade do rosto significa tomar não a semelhança, mas a simultaneidade dos semblantes, a inquieta potência que os mantêm juntos e os reúne em comum". Por isso, imagens do rosto podem ser pensadas como o lugar do outro que se transforma na promessa do meu próprio lugar assumindo caráter estético, ético e político. Argumentamos que estas fotografias constroem uma forma de experiência ética com o outro - e não simplesmente apresentam uma face como se fosse rosto - o que se expõe é o gesto operativo da arte, a ficção criadora, enfim, "o gesto que desenha um espaço comum" (Rancière, 2010b, p. 22).

O rosto é o que alude à responsabilidade dos homens perante o sofrimento de seus semelhantes, é uma espécie de interpelação ética dirigida a nós: somos intimados a uma resposta, ao acolhimento de outrem, totalmente distinto de mim. Perante o rosto, somos afetados em nossos projetos e a legítima defesa é para sempre atravessada pelo imperativo "não matarás", enunciado pelo rosto.

Assim, as obras de Margolles respondem à interpelação dos rostos que convocam a partir das faces esmaecidas nas fotografias: imaginar apesar de tudo, não esquecer nem compactuar com o horror e a violência, mas responder ao rosto que se ergue dos cartazes e das fotografias. Margolles cria uma paisagem audiovisual na qual ecoa um agônico grito silencioso. O dizer do rosto nos apresenta uma dimensão sensível que não pode ser encampada totalmente pelo visível.

Contemplar o rosto numa imagem ou o rosto da imagem significa estabelecer com ela uma relação ética, uma relação de implicação, afetação e interpelação que nos torna disponíveis à escuta, ao diálogo e à reciprocidade, instaurando uma via de acolhida e hospitalidade do outro, sem reduzi-lo. Esse equilíbrio entre a aproximação (abertura) e o distanciamento é o que configura a condição de possibilidade de toda e qualquer forma de comunicação, de constituição de comunidades sensíveis.

\footnotetext{
${ }_{5}^{5}$ Uma discussão mais atenta sobre o conceito de rosto em Levinas em perspectiva com imagens fotográficas de vítimas se apresenta em outro artigo (Biondi \& Marques, 2016).
} 


\section{CONSIDERAÇÕES FINAIS}

Ao retomar a questão conflituosa entre singularidade e estereotipagem dos rostos que emergem na fotografia artística e naquela midiática, jornalística, consideramos interessante refletir algumas considerações que Didi-Huberman (2011, p. 67) tece acerca dos chamados "povos sem rosto". Segundo o autor, "povo sem rosto constitui a classe oprimida, exposta a desaparecer ou a ser subexposta nas representações consensuais da história" (Didi-Huberman, 2011, p. 67). Neste texto buscamos, através da análise das imagens selecionadas, indicar os elementos capazes de apontar para um tipo de resistência às formas de vida prontas, ao apagamento e desaparição dos sujeitos em narrativas que apenas encaixam os indivíduos em molduras discursivas previamente arquitetadas, que capturam seus gestos, rotinas e corpos em operações consensuais, constrangimentos e submissões de toda ordem.

No movimento e gesto políticos de exposição ligados a uma nova forma de aparecer, trazida pelas obras de Margolles, os indivíduos se transformam em sujeitos dotados de rosto, tal qual o entende Levinas, capazes de desenvolver capacidades enunciativas e demonstrativas de reconfigurar a relação entre o visível e o dizível, entre palavras e corpos. As imagens de Margolles convidam à aproximação ao outro, ao mesmo tempo em que assegura uma separação: se ela "produz uma ligação entre sujeitos separados, entre sujeitos da desligação, ela assegura a distância que os separa, preservando-os de qualquer fusão identificadora ou massificante" (Mondzain, 2011, p. 124). A partir da noção de rosto,que não é propriamente a face humana, mas um vestígio da presença de um Outro, por mais que esteja próximo, mantém-se à distância. Por isso, ele é comunicação e linguagem, aparição e desaparição, possibilidade de alcançar o Outro em sua infinitude (Souza \& Marques, 2016).

A vida residual das mulheres apresentadas no trabalho de Margolles inquire a condição de vulnerabilidade e de precariedade através de mecanismos de controle e subexposição que, em geral, conduz à desaparição social, à impessoalidade e à desumanização. Podemos dizer que através do que através do questionamento persistente das fotografias de Margolles uma micropolítica da resistência pode finalmente aparecer, reinventando os regimes de enunciação na imagem, através da imagem. A perda do rosto se configura pelo processo de enquadramento institucional, discursivo e social que dificulta a escuta do clamor do outro e, assim, a produção da responsabilidade ética sobre esse outro fragilizado e brutalizado.

Por meio das fotografias das faces dessas mulheres, Margolles busca, ao contrário, conferir-lhes um rosto, onde a dignidade do ser humano é construída por meio de um olhar que escuta o rosto. Ela nos apresenta uma exposição de mulheres anônimas, acolhendo-as e acolhendo os sons de seu sofrimento via escuta e captura das suas faces. É claro que uma fotografia não devolve a palavra ao sujeito fotografado. Como ressalta Didi-Huberman (2012, p. 43), as imagens não restituem o nome próprio às pessoas cujos rostos estão expostos. Seu intuito é outro; trata-se de erguer os rostos, sustentá-los, dar-lhes o poder de faire face. E isso, a nosso ver, já significa expô-los na dimensão de uma possibilidade de palavra e de escuta. 


\section{REFERÊNCIAS BIBLIOGRÁFICAS}

Agamben, G. (2000). The face. In G. Agamben, Means without end: notes on politics (pp. 91-200). Minneapolis: University of Minnesota Press.

Biondi, A. \& Marques, A. (2016). Omayra: reflexões sobre o rosto, uma fotografia e suas políticas. Galáxia, 33, 145-157.

Biroli, F. (2016). Autonomia, preferências e assimetria de recursos. Revista Brasileira de Ciências Sociais (RBCS), 31(90), 39-57.

Blay, E. (2008). Assassinato de Mulheres e Direitos Humanos. São Paulo: Editora 34.

Butler, J.; Gambetti, Z. \& Sabsay, L. (2016). Vulnerability in resistance. Duke: Duke University Press.

Butler, J. (2006). Vida precaria. El poder del duelo y da violencia. Buenos Aires: Paidós.

Butler, J.(2011). Vida precária. Contemporânea Revista de Sociologia da UFSCar, 1, 13-33.

Butler, J.(2015). Relatar a si mesmo. Belo Horizonte: Autêntica.

Carcedo, A. (2010). No olvidamos ni aceptamos: Femicidio en Centroamérica 2000-2006. San Jose: CEFEMINA Associación Centro Feminista de Información y Acción. Retirado de http://www.sidocfeminista.org/ images/books/13189/13189_oo.pdf

Caldeira, B. (2017). Entre assassinatos em série e uma série de assassinatos: o tecer da intriga nas construções narrativas de mulheres mortas e seus agressores nas páginas de dois impressos mineiros. Dissertação de Mestrado, UFMG-FAFICH, Brasil.

Didi-Huberman, G. (2003). Images malgré tout. Paris: Éditions de Minuit.

Didi-Huberman, G. (2008). La emoción no dice "yo": diez fragmentos sobre la libertad estética. In A. Jaar (Ed.), La política de las imágenes (pp. 39-67). Santiago de Chile: Editorial Metales Pesados.

Didi-Huberman, G. (2011). Sobrevivência dos vaga-lumes. Belo Horizonte: Ed. UFMG.

Didi-Huberman, G. (2012). Peuples exposés, peuples figurants: L'Oeil de l'Histoire, 4. Paris: Éditions de Minuit.

Didi-Huberman, G. (2014). Grisalha: poeira e poder do tempo. Lisboa: KKYM + IHA.

Fassin, D.; Rechtman, R. (2007). L'Empire du traumatisme. Enquête sur la condition de victime. Paris: Flammarion.

Fassin, D. (2014). Del'invention du traumatisme à la reconnaissance des victimes. Genèse et transformation d'une condition morale, Vingtième Siècle. Revue d'histoire, 123, 161-171.

Levinas, E. (1999). Alterity and transcendence. Nova lorque: Columbia University Press.

Levinas, E. (1982). Ética e infinito. Lisboa: Edições 70.

Levinas, E. (2011). De outro modo que ser ou para lá da essência. Lisboa: Centro de Filosofia da Universidade de Lisboa.

Marques, Â. (2014). Política da imagem, subjetivação e cenas de dissenso. Discursos Fotográficos, 10, 61-86.

Mondzain, M.-J. (2009). A imagem pode matar? Lisboa: Nova Vega. 
Mondzain, M.-J. (2011). Nada Tudo Qualquer coisa ou a arte das imagens como poder de transformação. In R. Silva \& L. Nazaré (Eds.), A república por vir. Arte, política e pensamento para o século XXI (pp. 103-138). Lisboa: Fundação CalousteGulbekian.

Picado, J.B. (2014). O olho suspenso do novecento: plasticidade e discursividade visual no fotojornaismo moderno. Rio de Janeiro: Pensamento Brasileiro.

Pignotti, D. (2012, 23 de setembro). Cidade Juarez: um retrato da violência sem fim no México. Carta Maior. Retirado de http://www.cartamaior.com.br/?/Editoria/Internacional/ Cidade-Juarez-um-retrato-da-violencia-sem-fim-no-Mexico/6/25968\#

Rancière, J. (2004). Aux bords du politique. Paris: Gallimard.

Rancière, J. (2006). Le coup double de l'art politisé: entretien avec Gabriel Rockhill. Lignes, 1(19), 141-164.

Rancière, J. (2007). Le travail de l'image. Multitudes, 28, 195-210.

Rancière, J. (2009). Política de Pedro Costa. In R. M. Cabo (Ed.), Cem Mil Cigarros - os filmes de Pedro Costa (pp. 53-63). Lisboa: Orfeu Negro.

Rancière, J. (2010a). O espectador emancipado. Lisboa: Orfeu Negro.

Rancière, J. (2010b). A estética como política. Revista Devires, 7(2), 14-36.

Rancière, J. (2012). O destino das imagens. Rio de Janeiro: Contraponto.

Russell, D. \& Harmes, R. (2001). Defining femicide and related concepts. In D. Russel \& R. Harmes (Eds.), Femicide in Global Perspective (pp. 12-28). Nova lorque: Teacher's College Press.

Souza, F. C. V. \& Marques, A. (2016). Rosto e cena de dissenso: aspectos éticos, estéticos e comunicacionais de constituição do sujeito político. Questões Transversais - Revista de Epistemologias da Comunicação, 4 , $17-27$.

Tassin, E. (2004). La question de l'apparence. In F. Collin (Ed.), Politique et Pensée: Colloque Hannah Arendt (pp. 69-94). Paris: Éditions Payot \& Rivages.

\section{FinANCIAMENTo}

CAPES - Coordenação de Aperfeiçoamento de Pessoal de Nível Superior; CNPq Conselho Nacional de Desenvolvimento Científico e Tecnológico.

\section{NOTAS BIOGRÁFICAS}

Ângela Cristina Salgueiro Marques é Professora do Programa de Pós-graduação em Comunicação Social da Universidade Federal de Minas Gerais (UFMG). Doutora em Comunicação Social pela UFMG e pós-doutorado em Ciências da Informação e Comunicação pela Université Stendhal, Grenoble III, França. Seus atuais interesses de pesquisa estão voltados para a interseção entre a Comunicação, a Política e a Estética; entre a Comunicação e a Cultura, e entre a Comunicação e processos políticos, privilegiando os devires minoritários, as resistências e as insurgências cotidianas.

E-mail: angelasalgueiro@gmail.com 
Rua Castelo de Avis, 193, apto.201, Bairro Castelo. Cep: 31330-110. Belo Horizonte, MG, Brasil

Angie Gomes Biondi é Professora do Programa de Pós-graduação em Comunicação e Linguagens da Universidade Tuiuti do Paraná (UTP). Doutora em Comunicação Social pela UFMG e pós-doutorado pela Université du Québec à Montréal, Canadá. Seus interesses de pesquisa abrangem os processos sociais e comunicacionais que envolvem corpo, imagem e sociabilidade articulados à reflexão sobre as políticas de visibilidade e formas de subjetivação contemporâneas.

E-mail: angiebiondina@gmail.com

Travessa Rafael Francisco Greca, 151, apto.153 B. Água Verde. Cep: 80.620-150. Curitiba - Paraná, Brasil

* Submetido: 31-07-2017

* Aceite: 05-11-2017 